\title{
-Fluorination of Nitrobenzenes and Nitropyridines via Vicarious Nucleophilic Substitution of Hydrogen
}

DOI:

10.1055/s-0039-1690862

\section{Document Version}

Accepted author manuscript

Link to publication record in Manchester Research Explorer

\section{Citation for published version (APA):}

Al-mkhaizim, F. Y., \& Greaney, M. F. (2020). -Fluorination of Nitrobenzenes and Nitropyridines via Vicarious Nucleophilic Substitution of Hydrogen. SYNLETT, 31(11), 1094-1096. https://doi.org/10.1055/s-0039-1690862

\section{Published in:}

SYNLETT

\section{Citing this paper}

Please note that where the full-text provided on Manchester Research Explorer is the Author Accepted Manuscript or Proof version this may differ from the final Published version. If citing, it is advised that you check and use the publisher's definitive version.

\section{General rights}

Copyright and moral rights for the publications made accessible in the Research Explorer are retained by the authors and/or other copyright owners and it is a condition of accessing publications that users recognise and abide by the legal requirements associated with these rights.

\section{Takedown policy}

If you believe that this document breaches copyright please refer to the University of Manchester's Takedown Procedures [http://man.ac.uk/04Y6Bo] or contact uml.scholarlycommunications@manchester.ac.uk providing relevant details, so we can investigate your claim.

\section{OPEN ACCESS}




\section{$\alpha$-Fluorination of Nitrobenzenes and Nitropyridines via Vicarious Nucleophilic Substitution of Hydrogen}

Fayez Y. Al-Mkhaizim

Michael F. Greaney*

School of Chemistry, University of Manchester, Oxford Rd, Manchester, M13 9PL, UK

Michael.greaney@manchester.ac.uk

Click here to insert a dedication<smiles>O=[N+]([O-])c1ccccc1</smiles><smiles>[R]C(Cl)C(=O)OCC</smiles>

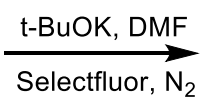<smiles>[R]C(F)(C(=O)OCC)c1ccc([N+](=O)[O-])cc1</smiles>

\section{Received:
Accepted:
Published online:}

Abstract A highly selective $\mathrm{C}-\mathrm{H}$ functionalization of nitrobenzenes and nitropyridines is reported using tandem vicarious nucleophilic substitution (VNS) chemistry with electrophilic fluorination using Selectfluor. The process generates tertiary benzylic fluorides in good yield under simple, mild conditions and short reaction times.

Key words Fluorination, vicarious nucleophilic substitution

C-H Functionalization of pyridines and electron poor nitroarenes is a challenging transformation, with few general methods available. Two of the most effective approaches are the radical Minisci reaction, ${ }^{1}$ and the anionic vicarious nucleophilic substitution (VNS) developed by Makosza. ${ }^{2}$ The VNS reaction employs a nucleophilic component such as an enolate or sulfone (2) containing an appropriate nucleofuge, and proceeds via $\mathrm{S}_{\mathrm{N}}$ addition to the nitrobenzene or pyridine to form Meisenheimer intermediate 3 . Elimination of $\mathrm{HX}$ under the basic reaction conditions can then take place, which upon protonation gives the $\mathrm{C}-\mathrm{H}$ functionalized electron poor arene product $\mathbf{5}$. The reaction proceeds under very simple conditions, albeit strongly basic ones, enables direct $\mathrm{C}-\mathrm{C}$ bond formation at azine positions that are hard to achieve any other way, and has thus seen extensive use in medicinal and agro-chemistry. ${ }^{3}$

A powerful extension of the Makosza VNS reaction is to add a third electrophilic component to the reaction mixture that can trap intermediate 4. This process can install quaternary stereocentres $\alpha$ to an azine or electron poor arene - a key structural motif of biologically active natural products and drug molecules that is difficult to install. The reaction has been exclusively exemplified with reactive carbon electrophiles such as methyl, benzyl, and allyl halides, epoxides, aldehydes, and

Michael acceptors ${ }^{4}$ (Scheme 1.2), we were interested in exploring the reaction in the context of heteroatom functionalization, by forming a C-F bond with an electrophilic fluorinating agent (Scheme 1.3). The process would assemble valuable secondary and tertiary benzylic fluorides, creating a C$\mathrm{C}$ and $\mathrm{C}-\mathrm{F}$ bond in a single operation, functionalizing a $\mathrm{C}-\mathrm{H}$ position on a pyridine or nitrobenzene ring. ${ }^{5}$

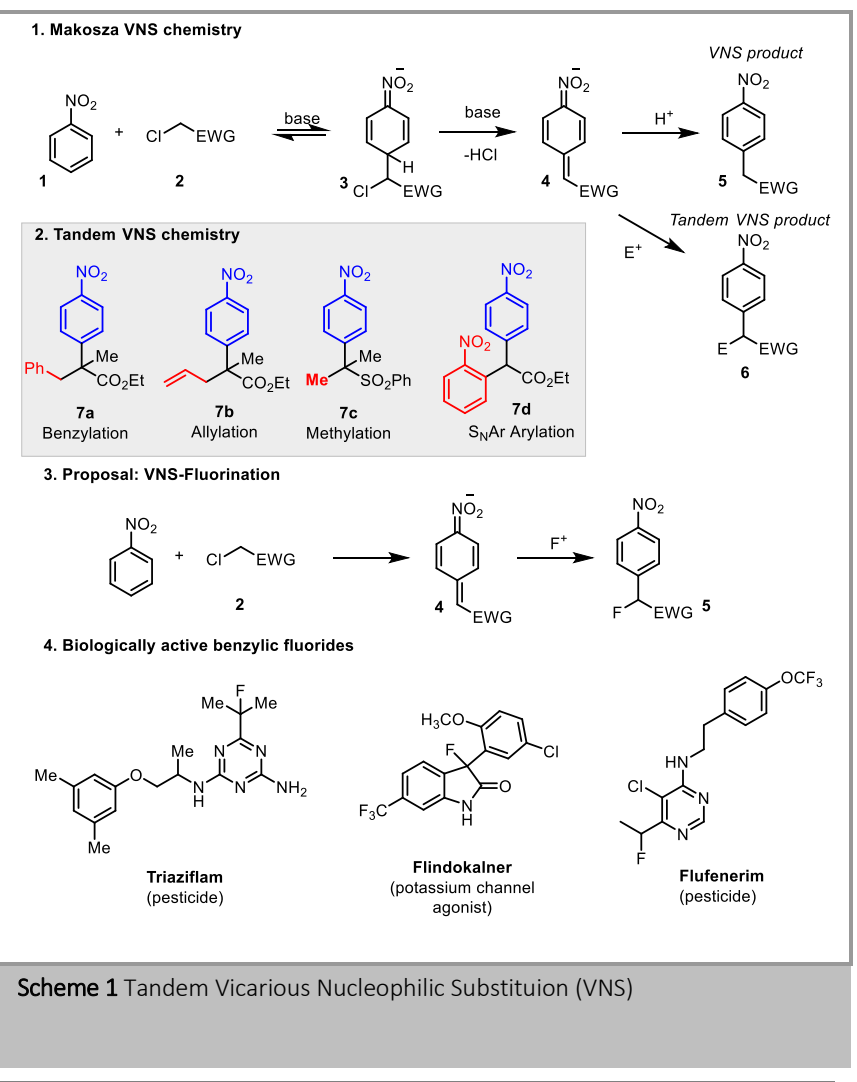


We began our study by examining the VNS addition of chloropropionate $\mathbf{2 a}$ to nitrobenzene, followed by electrophilic quench. tBuOK in DMF was an effective base, in line with the literature, but the reaction time was very important (Table 1). Short, 30 second VNS reaction followed by addition of electrophile was substantially more effective than longer stirring times (entry 2 versus entry 3). A discrete VNS reaction period was essential, however, as combining all three components from the start was not successful (entry 5). The requirement for shorter reaction times suggest a stability issue with either $\sigma$-adduct $\mathbf{3}$ or VNS structure $\mathbf{4}$ under these reaction conditions. This proved to be the case, as separate treatment of VNS product $\mathbf{5}$ with $\mathrm{t}$-BuOK in DMF at room temperature led to decomposition. The short VNS protocol was effective for benzylation (entry 3) and a novel arylation using diphenyliodonium triflate (entry 6).

Table 1 Optimization of VNS-Electrophilic Coupling ${ }^{[a]}$

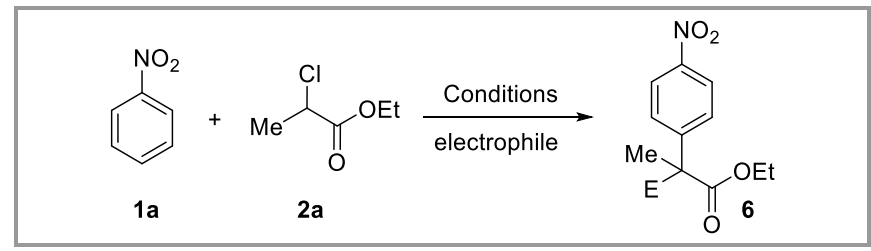

\begin{tabular}{ccccc}
\hline entry & bases & electrophiles & $\begin{array}{c}\text { time } \\
\text { (min) }\end{array}$ & yield \\
\hline $\mathbf{1}$ & NaH & Allyl Bromide & 100 & 10 \\
$\mathbf{2}$ & t-BuOK & Benzyl Bromide & 120 & 0 \\
$\mathbf{3}$ & t-BuOK & Benzyl Bromide & 0.5 & 95 \\
$\mathbf{4}$ & t-BuOK & Allyl Bromide & 0.5 & 70 \\
$\mathbf{5}$ & t-BuOK & Allyl Bromide & 0 & 0 \\
$\mathbf{6}$ & t-BuOK & Diphenyliodonium & 0.5 & 50 \\
& & triflate & &
\end{tabular}

a Reaction of 1a (1 eq.), 2a (1.1 eq.) and base (5 eq.) in DMF (2 mL/mmol) stirred in a closed $4 \mathrm{~mL}$ vial at room temperature under nitrogen. Electrophile then added ( 2 eq.) and stirred for a further 60 minutes.

We then turned our attention to fluorination of the VNS intermediate. We elected to use selectfluor, as an easy to handle, readily available electrophilic fluorinating agent, and were pleased to observe successful reaction with a one minute VNS protocol, but only in moderate yield (Table 2, entry 1). In line with several VNS transformations in the literature, colder temperatures proved effective, with $-42{ }^{\circ} \mathrm{C}$ being optimal and delivering fluoride $\mathbf{8 a}$ in $86 \%$ yield. The reaction was somewhat sensitive to air and required inert atmosphere for best results (entry 4), the nitronate (intermediate $\mathbf{3}$ in Scheme 1) being well known to undergo oxidative aromatization. ${ }^{2}$

The reaction was scoped for a variety of nitrobenzene and pyridine acceptors (Scheme 2). The nitrobenzene scope gave good to excellent yields with various electron-withdrawing and donating groups in the 2-position, with selective para addition observed in each case $(\mathbf{8 a}-\mathbf{8 e})$. Variation of the enolate was possible with phenyl substitution $(\mathbf{8 g})$ and the useful chlorofluoro functionality $\mathbf{8 f}$, installed starting from $\alpha, \alpha$ dichlorofluoro propionate. We were pleased to find the reaction was also successful for nitropyridines, with a longer initial VNS addition time of 45 minutes prior to selectfluor addition. Addition was observed to take place ortho to pyridine nitrogen, in line with literature observations from Makosza on enolate VNS additions to similar substrates. ${ }^{6}$

Table 2. Optimization of VNS-Fluorine Coupling ${ }^{[a]}$

\begin{tabular}{cccc}
\hline & & & \\
\hline entry & temp. & time (min) & yield \\
\hline $\mathbf{1}$ & 0 & 1 & 27 \\
$\mathbf{2}$ & -15 & 1 & 70 \\
$\mathbf{3}$ & -42 & 1 & 86 \\
$\mathbf{4}^{[\mathrm{b}]}$ & -42 & 1 & 85 \\
$\mathbf{5}$ & -72 & 1 & 62 \\
\hline
\end{tabular}

${ }^{\text {[a] }}$ Reaction of 1a (1 eq.), 2a (1.1 eq.) and t-BuOK (5 eq.) in DMF $(2 \mathrm{~mL} / \mathrm{mmol})$, stirred for $1 \mathrm{~min}$. in a closed $4 \mathrm{~mL}$ vial at room Temperature under nitrogen. Selectfluor (2 eq.) added and stirred for a further 60 minutes. ${ }^{[b]}$ Reaction done in the presence of air.

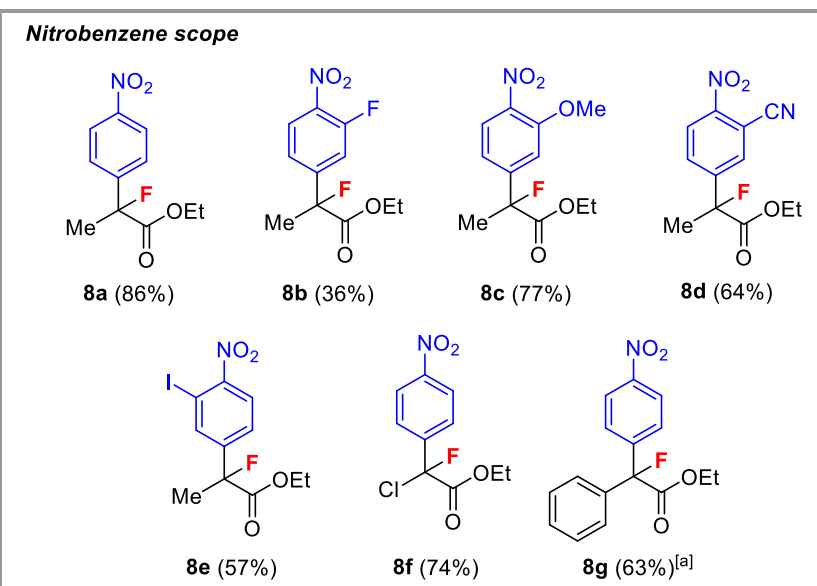

Pyridine scope<smiles>CCOC(=O)C(C)(F)c1nc(OC)ccc1[N+](=O)[O-]</smiles>

9a $(85 \%)$<smiles>CCOC(=O)C(C)(F)c1ccc([N+](=O)[O-])cn1</smiles>

9 b $(41 \%)$<smiles>CCOC(=O)C(F)(F)c1nc(OC)ccc1[N+](=O)[O-]</smiles>

9c $(90 \%)$<smiles>CCOC(=O)C(F)c1nc(OC)ccc1[N+](=O)[O-]</smiles>

9d $(43 \%)$
Scheme 2 VNS Fluorination substrate scope. ${ }^{7}$

${ }^{\text {[a] }}$ Product isolated with ca. $10 \%$ co-running impurity.

In summary, we have developed a one-pot method of generating fluorinated quaternary carbon centers $\alpha$ to nitroarene and azine rings. The reaction proceeds under mild conditions with generally good yields and regio-selectivities through a VNS mechanism. Further applications of this fluorination process are being investigated in our laboratory. 


\section{Funding Information}

We thank the Government of Kuwait for a PhD studentship to F. Y. A.-M.

\section{Supporting Information}

YES (this text will be updated with links prior to publication)

\section{References and Notes}

(1) Proctor, R. S. J.; Phipps, R. J. Angew. Chem. Int. Ed. 2019, 58, 13666.

(2) Makosza, M.; Wojciechowski, K. Chem. Rev. 2004, 104, 2631.

(3) Makosza, M.; Wojciechowski, K. Liebigs Ann. Chem. 1997, 9, 1805.

(4) a) Jackson, D. A.; Lawrence, N. J.; Liddle, J. Synlett 1996, 55. b) Brown, K. M.; Jackson, D. A.; Lawrence, N. J.; Liddle, J.; Muhammad, F. Tetrahedron Lett. 1994, 35, 6733. c) Bushell, S. M.; Crump, J. P.; Lawrence, N. J.; Pineau, G. Tetrahedron 1998, 54, 2269. d) Lawrence, N. J.; Lamarche, 0.; Thurrab, N. Chem. Commun. 1999, 689. e) Lawrence, N. J.; Liddle, J.; Bushell, S. M.; Jackson, D. A. J. Org. Chem. 2002, 67, 457. f) Lawrence, N. J.; Liddle, J.; Jackson, D. J. Chem. Soc., Perkin Trans. 1, 2002, 2260. g) Florio, S.; Lorusso, P.; Granito, C.; Ronzini, L.; Troisi, L. Eur. J. Org. Chem. 2003, 4053. h) Florio, S.; Lorusso, P.; Granito, C.; Luisi, R.; Troisi, L. J. Org. Chem. 2004, 69, 4961. i) Lawrence, N. J.; Davies, C. A.; Gray, M. Org. Lett. 2004, 6, 4957. j) Cao, S.; Wu, J.; Li, L.; Zhu, L.; Zhang, J.; Yu, J.; Qian, X. Org. Biomol. Chem. 2008, 6, 1293. k) Beier, P.; Pastyrikova, T.; Iakobson, G. J. Org. Chem. 2011, 76, 4781. l) Makosza, M.; Bester, K.; Cmoch, P. J. Org. Chem. 2015, 80, 5436. m) Sakowicz, A.; Loska, R.; Makosza, M. Synlett 2016, 2443. n) Loska, R. Eur. J. Org. Chem. 2018, 6649.

(5) For a review of benzylic fluorination, see: Koperniku, A.; Liu, H.; Hurley, P. B. Eur J. Org. Chem. 2016, 871.
(6) Czaban-Joźwiak, J.; Loska, R.; Makosza, M. J. Org. Chem. 2016 81, 11751.

(7) Tandem VNS Fluorination - General procedure for nitrobenzenes

In a dry $5 \mathrm{~mL}$ microwave vial containing a stir bar, the nitrobenzene (1 equiv) and VNS nucleophile (1.1 equiv) were added and the vial sealed. The vial was then evacuated and filled with nitrogen three times before adding dry DMF. The vial is then cooled to the $-42{ }^{\circ} \mathrm{C}$. In another $5 \mathrm{~mL}$ microwave vial t-BuOK ( 5 equiv) was added before sealing the vial and adding dry DMF. The butoxide solution was syringed into the main vial and the reaction was left to stir for 1 minute before a solution of Selectfluor ( 2 equiv) was added. The reaction was then left to stir for a further 60 minutes. The solution was then diluted with ethyl acetate and washed with $1 \mathrm{M} \mathrm{HCl}(1 \times 5$ $\mathrm{mL})$ and brine $(2 \times 50 \mathrm{~mL})$. The organic extract was then dried over $\mathrm{Na}_{2} \mathrm{SO}_{4}$, the solvent removed in vacuo, and the crude product purified by column chromatography.

\section{Ethyl 2-fluoro-2-(4-nitrophenyl)propanoate, 8a}

Colorless oil. (260 mg, 86\%). ${ }^{1} \mathrm{H}$ NMR (500 MHz, Chloroform-d) $\delta$ $8.16(\mathrm{~d}, \mathrm{~J}=8.9 \mathrm{~Hz}, 2 \mathrm{H}), 7.66(\mathrm{~d}, \mathrm{~J}=9.0 \mathrm{~Hz}, 2 \mathrm{H}), 4.18(\mathrm{~m}, 2 \mathrm{H}), 2.08(\mathrm{~s}$, $3 \mathrm{H}), 1.18(\mathrm{t}, \mathrm{J}=7.1 \mathrm{~Hz}, 3 \mathrm{H}) \cdot{ }^{13} \mathrm{C}$ NMR (126 MHz, Chloroform- $d$ ) $\delta$ 169.6, 148.0, 145.9, 125.7, 123.7, 94.2 (d, J = $189.6 \mathrm{~Hz}), 62.6,25.2$, 14.0. ${ }^{19} \mathrm{~F}$ NMR (471 MHz, Chloroform-d) $\delta-153.66(\mathrm{q}, \mathrm{J}=22.8 \mathrm{~Hz}$ ). HRMS (ESI) $\left(\mathrm{M}+\mathrm{H}^{+}\right)$calcd for $\mathrm{C}_{11} \mathrm{H}_{14} \mathrm{NO}_{4} \mathrm{~F}$ : 242.0823; found: 242.0819 